\title{
ANÁLISE MORFOMÉTRICA DA BACIA HIDROGRÁFICA PARAGUAI/JAUQUARA, MATO GROSSO - BRASIL
}

Angélica Aparecida Dourado da Costa ${ }^{1}$ Edinéia Aparecida dos Santos Galvanin² Sandra Mara Alves da Silva Neves ${ }^{3}$

Resumo: A análise morfométrica de bacias hidrográficas fornece dados que possibilitam a compreensão do regime hidrológico, bem como das vulnerabilidades quanto a enchentes, inundações, erosões e à manutenção da rede de drenagem. Nesse contexto, este artigo teve o objetivo analisar a morfometria da Bacia Hidrográfica Paraguai/Jauquara, Mato Grosso. Os dados para os cálculos de 14 parâmetros morfométricos foram gerados, armazenados e processados por meio de geotecnologias. Os resultados indicaram que a bacia é vulnerável quanto à manutenção da rede de drenagem, causando preocupação, pois isso pode afetar a sua dinâmica hídrica, o uso múltiplo das águas e influenciar no pulso de inundação do Pantanal mato-grossense.

Palavras-chave: Recursos Hídricos. Unidade de Gestão. Sensoriamento Remoto. Uso da Terra.

\section{MORPHOMETRIC ANALYSIS OF THE PARAGUAI/JAUQUARA HYDROGRAPHIC BASIN IN MATO GROSSO - BRAZIL}

Abstract: The morphometric analysis of hydrographic basin provides data that allow the hydrological regime understanding, as well as vulnerabilities to flooding, inundation, erosion and drainage network maintenance. In this context, this article aims to analyze the Paraguai/Jauquara basin morphometry, in Mato Grosso. The data for the calculations of 14 morphometric parameters were generated, stored and processed through geotechnologies. The results indicated that the basin is vulnerable to the drainage network maintenance, causing concern because it can affect its water dynamics, the multiple use of waters and influence on the inundation pulse of Pantanal, Mato Grosso.

Keywords: Water Resources. Management Unit. Remote Sensing. Land Use.

\section{ANÁLISIS MORFOMÉTRICA DE LA BACIA HIDROGRÁFICA PARAGUAY/JAUQUARA, MATO GROSSO - BRASIL}

Resumen: El análisis morfométrico de cuencas hidrográficas proporciona datos que posibilitan la comprensión del régimen hidrológico, así como de las vulnerabilidades cuanto a inundaciones, desbordamientos, erosiones y mantenimiento de la red de drenaje. En este contexto, este artículo tiene como objetivo analizar la morfometría de la Cuenca Hidrográfica Paraguay/Jauquara, Mato Grosso. Los datos para los cálculos de 14 parámetros morfométricos fueron generados, almacenados y

\footnotetext{
${ }^{1}$ Universidade do Estado de Mato Grosso - UNEMAT, Estudante de Mestrado, Tangará da Serra-MT, Brasil, angelica.dourado.jna@gmail.com, https://orcid.org/0000-0002-9104-9429

${ }^{2}$ Universidade Estadual Paulista - UNESP, Departamento de Geografia, Ourinhos-SP, Brasil, edineia.galvanin@unesp.br, https://orcid.org/0000-0002-6678-9599

${ }^{3}$ Universidade do Estado de Mato Grosso - UNEMAT, Departamento de Geografia, Cáceres-MT, Brasil, ssneves@unemat.br, https://orcid.org/0000-0002-2065-244X
} 
procesados por medio de geotecnologías. Los resultados indicaron que la cuenca es vulnerable en lo que se refiere al mantenimiento de la red de drenaje causando preocupación, pues puede afectar su dinámica hídrica, el uso múltiple de las aguas y influir en el pulso de inundación del Pantanal mato-grossense.

Palabras-clave: Recursos Hídricos. Unidad de Gestión. Detección Remota. Uso de la Tierra.

\section{Introdução}

Os mananciais que compõem as bacias hidrográficas desempenham papel fundamental no desenvolvimento socioeconômico da sociedade, sendo utilizados para o abastecimento humano, a dessedentação de animais, o uso das indústrias, a geração de energia, a irrigação na agricultura, entre outros usos. Portanto, a qualidade, disponibilidade e continuidade da utilização da água dependem de uma gestão integrada que envolva interesses sociais, econômicos, ambientais e outros (TUCCI, 2001).

Em face da importância desse componente ambiental, a Política Nacional de Recursos Hídricos (PNRH), instituída pela Lei Federal n. ${ }^{\circ}$ 9.433, de 8 de janeiro de 1997 (BRASIL, 1997), designa as bacias hidrográficas como unidades territoriais para estudo, gestão e gerenciamento dos recursos hídricos (BRASIL, 1997), pois estas são áreas delimitadas por divisores topográficos que captam naturalmente a água precipitada, assim, constituindo os canais de escoamento (rede de drenagem) que confluem até formarem um canal principal, direcionado a um único ponto de saída, denominado exutório (VILLELA; MATTOS, 1975).

Segundo Soares et al. (2016), uma das estratégias de gerenciamento de uma bacia hidrográfica é a compreensão de suas características físicas que compõem um conjunto de indicadores interdisciplinares que possibilitam analisar sua dinâmica ambiental e territorial em sua área de abrangência. Nesse sentido, a caracterização morfométrica de uma bacia hidrográfica é o primeiro método de avaliação a ser realizado (TEODORO et al., 2007).

Villela e Mattos (1975) explicam que o estudo das características físicas, ou seja, da morfometria de uma bacia, pode ser utilizado para estabelecer relações e comparações com as características morfológicas de outras bacias, dessa forma, possibilita a identificação indireta dos dados hidrológicos de locais que, por fatores econômicos e logísticos, não sejam possíveis de obter. Sobre o assunto, Christofoletti (1981) sugere que os parâmetros utilizados em uma caracterização morfométrica englobem as seguintes caracterizações: areal, linear e hipsométrica, 
sendo que a linear depende das medições feitas ao longo dos canais de escoamento; a areal necessita de medições planimétricas e dos canais de escoamento (lineares); e a hipsométrica estuda a inter-relação da declividade em relação às faixas de altitude, assim, indicando sua proporção na bacia hidrográfica.

Desse modo, a análise da morfometria pode elucidar questões relacionadas à dinâmica hídrica, local e regional, permitindo a investigação e compreensão científica dos componentes naturais de uma bacia hidrográfica (TEODORO et al., 2007; SANTOS; MORAIS, 2012;).

Estudos morfométricos que visam caracterizar, avaliar e analisar bacias hidrográficas, como os de Borsato e Martoni (2004) e Santos et al. (2007), em ambiente de Sistemas de Informações Geográficas (SIG), por meio da utilização de geotecnologias (Sensoriamento Remoto, Sistemas de Informação Geográfica, Banco de Dados Geográficos, dentre outras), demonstram ser eficientes na geração de dados que possibilitam o entendimento da dinâmica hídrica de bacias hidrográficas.

Diante do exposto, o objetivo deste estudo é analisar a morfometria da Bacia Hidrográfica Paraguai/Jauquara, no estado de Mato Grosso.

O estudo morfométrico da Bacia Hidrográfica Paraguai/Jauquara (BHPJ) possibilitará à sociedade e à gestão governamental compreenderem a sua dinâmica hídrica e as vulnerabilidades hidrológicas da bacia de estudo, considerando que esta se localiza em regiões do Planalto, possui extensa área de drenagem e contribui diretamente para o pulso de inundação do Pantanal mato-grossense (PESSOA et al., 2013).

\section{Área de Estudo}

A BHPJ possui uma área de drenagem de $16.482 \mathrm{~km}^{2}$, contida na porção nordeste da Bacia do Alto Paraguai (BAP) (Figura 1). Está localizada na região Sudoeste de planejamento do estado de Mato Grosso, abrangendo 16 municípios (MATO GROSSO, 2017). Sua extensão abrange áreas do Planalto do Parecis, da Província Serrana, Planícies e Pantanais mato-grossenses e a Depressão do Rio Paraguai (CASARIN; NEVES; NEVES, 2008). 


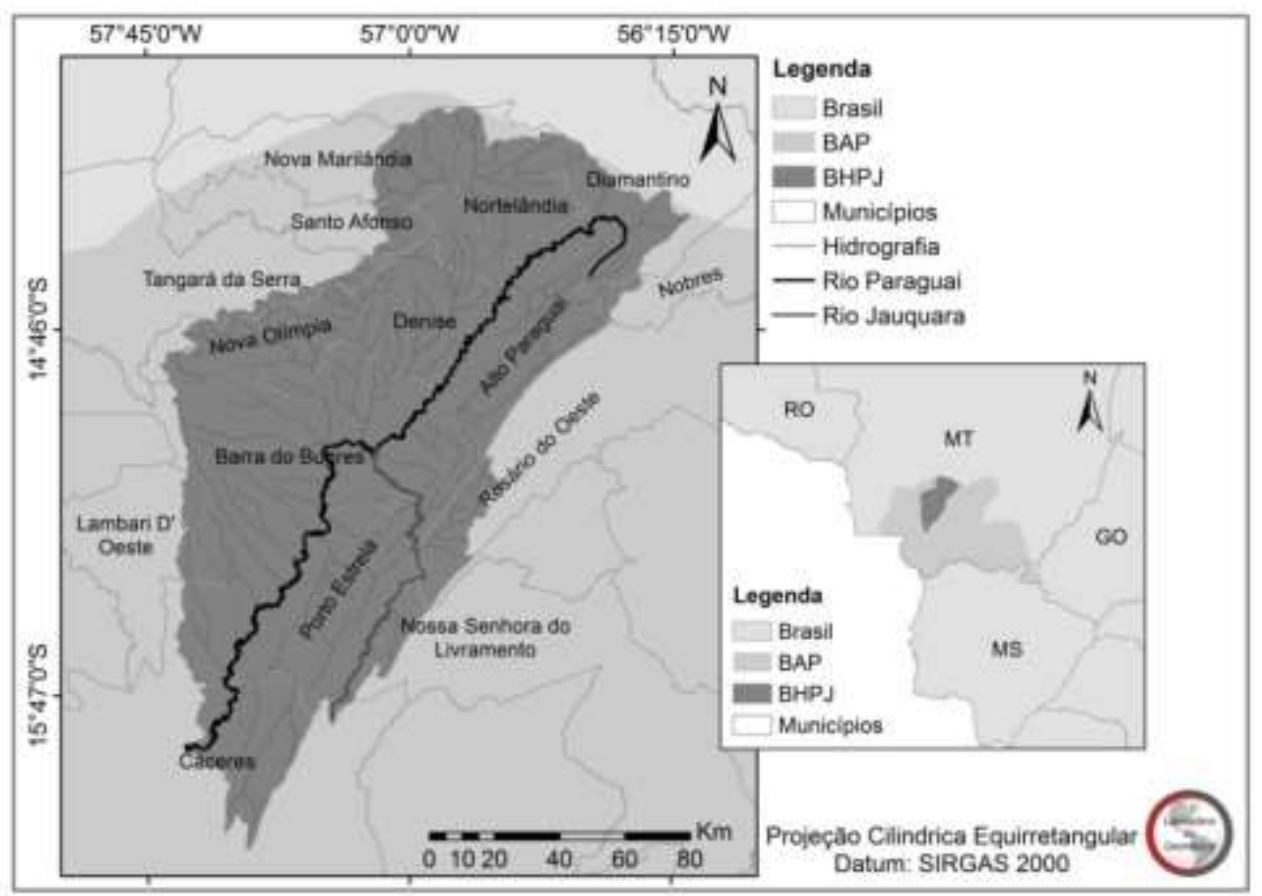

Figura 1 - Bacia Hidrográfica Paraguai/Jauquara nos contextos da Bacia do Alto Paraguai no Mato Grosso e municipal. Elaboração: A autora (2018)

$\mathrm{Na}$ bacia, predominam três tipos de solos: Latossolo Vermelho Distrófico, Latossolo Vermelho-Amarelo Distrófico e Argissolo Vermelho-Amarelo Distrófico (SANTOS et al., 2013). Além disso, abarca porções dos biomas Amazônia, Cerrado e Pantanal, predominando as fitofisionomias de Savanas e Florestas Estacionais (BRASIL, 2004; IBGE, 2012).

O clima é Tropical, com duas estações bem definidas, a de chuva, que ocorre nos meses de outubro a abril, e a de seca, de maio a novembro (FENNER et al., 2014). No ano de 2017, a pluviosidade atingiu $1.642 \mathrm{~mm} / \mathrm{ano}$, sendo que a máxima foi de $357 \mathrm{~mm}$, em fevereiro, e a mínima foi de $0 \mathrm{~mm}$, em junho e julho do mesmo ano (BRASIL, 2018).

A BHPJ contempla uma região formada por relevos dissecados e com elevadas altitudes, acima dos $700 \mathrm{~m}$. No seu território está localizada a Estação Ecológica Serra das Araras, que é uma unidade de conservação de proteção integral criada pelo Decreto n. 87.222, de 31 de maio de 1982 (BRASIL, 1982), com área de $271 \mathrm{~km}^{2}$, situada nos limites dos municípios de Cáceres e Porto Estrela.

A nascente do rio Paraguai está situada no município de Alto Paraguai, na porção nordeste da BHPJ. As águas dos tributários do rio Paraguai, como os rios dos Bugres, Branco, Diamantino, Pari, Santana e Jauquara e os córregos Cachoerinha e Salobra, situados no Mato Grosso, são indispensáveis para que ocorra o pulso de inundação do Pantanal, contido na BAP. 


\section{Procedimentos Metodológicos}

Neste estudo, foram selecionados 14 parâmetros, descritos por Horton (1945), Schumm (1956), Strahler (1957), Christofoletti (1981) e Villela e Mattos (1975), divididos em três categorias de caracterização: areal, linear e hipsométrica (Quadro 1).

Quadro 1 - Parâmetros morfométricos aplicados na análise da Bacia Hidrográfica Paraguai/Jauquara

\begin{tabular}{|c|c|c|}
\hline Parâmetros & Conceito & Expressão Matemática \\
\hline \multicolumn{3}{|c|}{ Análise Linear } \\
\hline $\begin{array}{c}\text { Hierarquia Fluvial } \\
\text { (STRAHLER, } 1957 \text { apud } \\
\text { CHRISTOFOLETTI, 1981) }\end{array}$ & $\begin{array}{l}\text { Os canais que não possuem } \\
\text { tributários são considerados de } 1^{\text {a }} \\
\text { ordem, os de } 2^{\underline{a}} \text { ordem originam- } \\
\text { se de tributários de } 1^{\text {a }} \text { ordem e os } \\
3^{\text {a }} \text { ordem são formados a partir da } \\
\text { confluência de canais de } 2^{\underline{a}} \\
\text { ordem e assim sucessivamente }\end{array}$ & - \\
\hline $\begin{array}{l}\text { Relação de bifurcação } \\
\text { (HORTON, 1945) }\end{array}$ & $\begin{array}{l}\text { É a relação entre o número total } \\
\text { de canais de uma ordem e o } \\
\text { número total de canais de outra } \\
\text { ordem imediatamente superior. } \\
\text { Pode variar de } 2 \text { para relevo } \\
\text { plano a suave ondulado e } 3 \text { a } 4 \\
\text { para relevo montanhoso ou } \\
\text { altamente dissecado }\end{array}$ & $\begin{array}{l}\qquad R b=\frac{N u}{\left(N_{u+1}\right)} \\
\text { Rb: Relação de bifurcação; Nu: } \\
\text { Número de canais por ordem; } \\
N_{u+1} \text { : Números de canais de } \\
\text { ordem imediatamente superior }\end{array}$ \\
\hline $\begin{array}{l}\text { Frequência de canais } \\
\text { (HORTON, 1945) }\end{array}$ & $\begin{array}{l}\text { Representa o número total de } \\
\text { canais por ordem hierárquica }\end{array}$ & $\begin{array}{l}\qquad F r=\frac{N u}{N t} x(100) \\
\text { Fr: Frequência de canais; Nu: } \\
\text { Número de canais por ordem; } \\
\text { Nt: Número total de canais }\end{array}$ \\
\hline $\begin{array}{l}\text { Comprimentos Médio dos } \\
\text { canais } \\
\text { (HORTON, 1945) }\end{array}$ & $\begin{array}{l}\text { Refere-se ao comprimento médio } \\
\text { dos cursos d'água de cada ordem }\end{array}$ & $\begin{array}{l}\qquad L m=\frac{L u}{N u} \\
\text { Lm: Comprimento médio dos } \\
\text { canais; Lu: Comprimento dos } \\
\text { canais de cada ordem; Nu: } \\
\text { Número de canais por ordem }\end{array}$ \\
\hline $\begin{array}{c}\text { Índice de sinuosidade } \\
\text { (VILLELA; MATTOS, } \\
\text { 1975) }\end{array}$ & $\begin{array}{c}\text { O índice relaciona o comprimento } \\
\text { do canal principal e o } \\
\text { comprimento de um talvegue }\end{array}$ & $\begin{array}{l}\qquad \operatorname{Sin}=\frac{L}{L t} \\
\text { Sin: Índice de sinuosidade; L: } \\
\text { Comprimento do canal principal; } \\
\text { Lt: Comprimento do talvegue }\end{array}$ \\
\hline $\begin{array}{l}\text { Gradiente do canal } \\
\text { principal } \\
\text { (HORTON, 1945) }\end{array}$ & $\begin{array}{c}\text { É a relação entre o comprimento } \\
\text { e a amplitude altimétrica de um } \\
\text { canal }\end{array}$ & $\begin{array}{l}\qquad G c p=\frac{A c p}{C c p} \\
\text { Gcp: Gradiente do canal } \\
\text { principal; Acp: Amplitude } \\
\text { Altimétrica do canal; Ccp: } \\
\text { Comprimento do canal }\end{array}$ \\
\hline \multicolumn{3}{|c|}{ Análise Areal } \\
\hline $\begin{array}{c}\text { Área de drenagem } \\
\text { (CHRISTOFOLETTI, 1981) }\end{array}$ & $\begin{array}{l}\text { Representa a área drenada pelo } \\
\text { sistema fluvial projetada em plano } \\
\text { horizontal }\end{array}$ & - \\
\hline $\begin{array}{l}\text { Índice de circularidade } \\
\text { (MILLER, } 1953 \text { apud } \\
\text { CHRISTOFOLETTI, }\end{array}$ & $\begin{array}{l}\text { Trata-se da relação entre a área } \\
\text { do círculo de mesmo perímetro }\end{array}$ & $I C=\frac{12,57 x A}{p^{2}}$ \\
\hline
\end{tabular}




\begin{tabular}{|c|c|c|}
\hline 1981) & & $\begin{array}{l}\text { IC: Índice de circularidade; A: } \\
\text { Área de um círculo; } \mathrm{p}^{2} \text { : } \\
\text { Perímetro do círculo ao } \\
\text { quadrado }\end{array}$ \\
\hline $\begin{array}{c}\text { Coeficiente de } \\
\text { compacidade } \\
\text { (VILLELA; MATTOS, } \\
\text { 1975) }\end{array}$ & $\begin{array}{l}\text { Conhecido também como índice } \\
\text { de Gravelius, determina a relação } \\
\text { do perímetro de um círculo de } \\
\text { uma área da mesma bacia }\end{array}$ & $\begin{array}{c}\text { kc }=0,28 x \frac{P}{\sqrt{A}} \\
\text { Kc: Coeficiente de } \\
\text { compacidade; P: Perímetro de } \\
\text { um círculo; A: Área de bacia }\end{array}$ \\
\hline $\begin{array}{c}\text { Densidade hidrográfica } \\
\text { (HORTON, 1945) }\end{array}$ & $\begin{array}{l}\text { Trata-se da relação entre o } \\
\text { número de canais e a área da } \\
\text { bacia, dessa forma, o propósito é } \\
\text { comparar a frequência de canais } \\
\text { por área de tamanho padrão }\end{array}$ & $\begin{array}{l}\qquad D r=\frac{N}{A} \\
\text { Dr: Densidade hidrográfica; N: } \\
\text { número total de canais; A: Área } \\
\text { da bacia }\end{array}$ \\
\hline $\begin{array}{l}\text { Densidade de drenagem } \\
\quad(\text { HORTON, 1945) }\end{array}$ & $\begin{array}{l}\text { A densidade de drenagem } \\
\text { relaciona o comprimento total dos } \\
\text { canais com a área da bacia. Pode } \\
\text { variar de } 0,5 \mathrm{~km} / \mathrm{km}^{2} \text {, para bacias } \\
\text { poucas drenadas, a } 3,5 \mathrm{~km} / \mathrm{km}^{2} \text { ou } \\
\text { mais, para bacias bem drenadas } \\
\text { (VILLELA; MATTOS, 1975) }\end{array}$ & $\begin{array}{l}\qquad D d=\frac{L}{A} \\
\text { Dd: Densidade de drenagem; L: } \\
\text { Comprimento total dos canais; } \\
\text { A: Área da bacia }\end{array}$ \\
\hline $\begin{array}{c}\text { Extensão do Percurso } \\
\text { Superficial } \\
\text { (CHRISTOFOLETTI, 1981) }\end{array}$ & $\begin{array}{l}\text { Representa a distância média } \\
\text { percorrida pela água da chuva } \\
\text { que teria de escoar em linha reta } \\
\text { até um canal permanente }\end{array}$ & $\begin{array}{c}\text { Eps }=\frac{1}{2 D d} \\
\text { Eps: Extensão do percurso } \\
\text { superficial; Dd: Densidade de } \\
\text { drenagem }\end{array}$ \\
\hline $\begin{array}{c}\text { Coeficiente de } \\
\text { manutenção } \\
\text { (SCHUMM,1956 apud } \\
\text { CHRISTOFOLETTI, 1981) }\end{array}$ & $\begin{array}{c}\text { Expressa a área mínima } \\
\text { necessária para manter a } \\
\text { manutenção de } 1 \mathrm{~m} \text { de um canal }\end{array}$ & $\begin{array}{c}\mathrm{Cm}=\frac{1}{\mathrm{Dd}} x(1000) \\
\mathrm{Cm}: \text { Coeficiente de } \\
\text { manutenção; Dd: Densidade de } \\
\text { drenagem }\end{array}$ \\
\hline \multicolumn{3}{|c|}{ Análise Hipsométrica } \\
\hline $\begin{array}{c}\text { Curva hipsométrica } \\
\text { (STRAHLER, } 1952 \text { apud } \\
\text { CHRISTOFOLETTI, 1981) }\end{array}$ & $\begin{array}{c}\text { É uma forma de representar } \\
\text { graficamente o relevo de uma } \\
\text { bacia, por meio da relação da } \\
\text { área com a altitude acima de uma } \\
\text { cota. Portanto, a curva } \\
\text { hipsométrica indica, em } \\
\text { porcentagem de área, a formação } \\
\text { de vales extensos e/ou profundos } \\
\text { em uma bacia }\end{array}$ & - \\
\hline
\end{tabular}

Fonte: Elaboração própria.

\section{Obtenção e Processamento dos Dados Espaciais}

Para realizar a caracterização e análise morfométrica da área de estudo foram utilizados os seguintes dados espaciais:

- Imagens do satélite Sentinel-2, com resolução espacial de $10 \mathrm{~m}$ e data de passagem referente aos meses de junho a setembro de 2017, adquiridas no sítio do Serviço Geológico dos Estados Unidos - United States Geological Survey (USGS, 2018). 
- Imagens do satélite Landsat-8, sensor Operational Land Imager (OLI), com resolução espacial de 30m, bandas 5-4-3 referentes à órbita 227 e pontos 070 e 071, imageadas nos dias 16/6/2017 e 19/8/2017, adquiridas no sítio do USGS.

- Modelo Digital de Elevação (MDE) Shuttle Radar Topography Mission (SRTM), com resolução espacial de $30 \mathrm{~m}$, disponibilizado no sítio do USGS.

- Cartas topográficas da Diretoria de Serviço Geográfico do Exército (DSG) disponibilizadas no sítio da SEPLAN/MT.

- Base cartográfica da hidrografia da BAP, disponível no sítio da Agência Nacional de Águas (ANA).

Os dados foram armazenados e processados em ambiente SIG. As imagens dos satélites foram georreferenciadas no software Sistema de Processamento de Informações Georreferenciadas (SPRING) (versão 5.5.2) (CÂMARA et al., 1996), a partir da ferramenta Registro de Imagens, bem como reprojeção para o Datum SIRGAS 2000 fuso 21 Sul, no software QGIS (versão 2.14.21) (QGIS DEVELOPMENT TEAM, 2016), com o auxílio da ferramenta Reprojetar.

As cenas do SRTM e do satélite Sentinel-2, com data de passagem de 16 de junho de 2017, foram mosaicadas no ArcGIS, módulo ArcMap (versão 10.3) (ESRI, 2007), por meio da ferramenta Mosaic to new raster.

A BHPJ foi delimitada a partir do MDE SRTM, no QGIS, por meio do complemento GRASS (versão 7.2.2). Foi aplicada a ferramenta r.watershed para delimitar o divisor topográfico da bacia, utilizando o valor mínimo (empírico) de 50.000 pixels, pois, quanto maior o número de pixels, menor a quantidade de bacias geradas.

Optou-se por delimitar a área de estudo e não usar o limite oficial do Sistema de Ottobacias da ANA, pois ele utiliza a escala do milionésimo e por isso não abrange canais de pequena drenagem, fundamentais para caracterizar a morfometria da bacia. A vetorização da hidrografia da bacia no módulo ArcMap foi feita por meio das cartas topográficas (escala 1:100.000) e das imagens do satélite Sentinel-2, já para classificação hierárquica dos cursos d'água foi adotada a metodologia de Strahler (1957 apud CHRISTOFOLETTI, 1981).

$\mathrm{Na}$ sequência, a área, o perímetro e os comprimentos dos canais da bacia foram calculados com o auxílio da ferramenta Calculate Geometry, no módulo ArcMap. Enquanto que as informações altimétricas da BHPJ foram extraídas do 
MDE do SRTM, por meio das curvas de nível com equidistância de $5 \mathrm{~m}$, via ferramenta Contorno do QGIS.

As imagens do satélite Landsat-8 foram classificadas, por meio do algoritmo de crescimento de regiões, adotando similaridade 3 e área de pixel 40, esses valores aplicados foram os que melhor representaram as regiões nas imagens, 0 algoritmo Bhattacharya foi treinado utilizando limiar de aceitação de 95\% no software SPRING. As classes de uso e cobertura foram identificadas conforme a apresentação do quadro 2.

Quadro 2 - Classes de uso e cobertura da terra identificadas na Bacia Hidrográfica Paraguai/Jauquara

\begin{tabular}{|l|l|}
\hline \multicolumn{1}{|c|}{ Classes } & \multicolumn{1}{c|}{ Descrição } \\
\hline Agricultura & Todos os tipos de culturas agrícolas \\
Corpos d'água & Lagos artificiais, lagoas, rios e espelhos d'água \\
Outros usos & Estradas vicinais, rodovias, construções civis, mineração, municípios e distritos \\
Pastagem & Pecuária \\
Vegetação & Savana e Floresta estacional \\
\hline
\end{tabular}

As Áreas de Preservação Permanente (APP) do canal principal da bacia foram delimitadas conforme definido na Lei Federal n. ${ }^{\circ}$ 12.651/2012 (BRASIL, 2012). Posteriormente, fez-se a intersecção das APPs, extraídas do mapa de uso e cobertura da terra, por meio da ferramenta Intersect do módulo ArcMap. Esse procedimento permitiu a avaliação da influência do uso e cobertura da terra no canal principal da BHPJ, por meio dos Índices de Sinuosidade e de Gradiente do Canal Principal com o Índice de Transformação Antrópica (ITA).

O ITA é calculado a partir das classes de uso e cobertura, utilizando a expressão matemática a seguir (LÉMECHEV, 1982).

$$
\mathrm{ITA}=\sum(\% \text { USO } \times \text { PESO }) \div 100
$$

onde: USO é o percentual de área das classes de uso e cobertura da terra e PESO é o peso atribuído aos diferentes tipos de usos e coberturas, variando de 1 a 10, sendo que 10 indica maior pressão antrópica (RIBEIRO; GALVANIN; PAIVA, 2017).

Os pesos para cada classe foram atribuídos conforme a observação multidisciplinar de pesquisadores da área de estudo, que, em consenso, estabeleceram os pesos, apresentados no quadro 3 (RIBEIRO; GALVANIN; PAIVA, 2017). 
Quadro 3 - Pesos atribuídos para o cálculo do Índice de Transformação Antrópica para as classes de uso e cobertura da terra na Bacia Hidrográfica Paraguai/Jauquara.

\begin{tabular}{|l|c|}
\hline \multicolumn{1}{|c|}{ Classes } & Pesos \\
\hline Vegetação & 1 \\
Corpos d'água & 2 \\
Pastagem & 5 \\
Agricultura & 7 \\
Outros usos & 9,5 \\
\hline
\end{tabular}

O resultado do ITA foi classificado em quartis (CRUZ et al. 1998), sendo considerados valores inferiores a 2,5 como Pouco Degradado; 2,5 a 5, Regular; 5 a 7,5, Degradado; e 7,5 a 10, Muito Degradado.

\section{Resultados e Discussão}

A BHPJ possui área de drenagem de $16.482,006 \mathrm{~km}^{2}$, classificada como grande, de acordo com Wisler e Brater (1964), pois ultrapassa $26 \mathrm{~km}^{2}$. A bacia possui uma forma mais alongada, pois o Índice de Circularidade obtido foi de 0,33 e o Coeficiente de Compacidade foi de 1,73, o que, segundo Villela e Mattos (1975), indica baixa propensão de ocorrência de enchentes devido à sua forma geométrica.

Borsato e Martoni (2004) complementam essa indicação explicando que bacias com essas características morfométricas apresentam precipitações mais distribuídas temporal e espacialmente, reduzindo as chances da ocorrência de enchentes, pois o total precipitado atinge grandes áreas da bacia em tempos alternados e, dessa forma, não excede a sua capacidade de escoamento até o exutório.

A BHPJ possui baixa Densidade Hidrográfica (Tabela 1), o que demanda preocupação, pois pode refletir na manutenção hidrográfica da bacia. Contudo, vale ressaltar que a BHPJ possui área de drenagem extensa e apresenta densidade hidrográfica alta na porção Leste e baixa na região Oeste, logo, permitindo compensação entre as maiores e menores capacidades de manutenção hidrográfica (Figura 2).

Tabela 1 - Caracterização Areal e Hipsométrica da Bacia Hidrográfica Paraguai/Jauquara

\begin{tabular}{l|l}
\multicolumn{1}{c}{ Parâmetros areais } & \multicolumn{1}{c}{ Resultados } \\
\hline Densidade Hidrográfica & 0,72 canais $/ \mathrm{km}^{2}$ \\
Densidade de Drenagem & $0,90 \mathrm{~km} / \mathrm{km}^{2}$ \\
Extensão do Percurso Superficial & $0,55 \mathrm{~km}$ \\
Coeficiente de Manutenção & $1,11 \mathrm{~km} / \mathrm{km}^{2}$ \\
\hline
\end{tabular}

A Densidade de Drenagem, que representa a relação inversa da extensão do escoamento superficial dos canais e, por isso, indica a eficiência da drenagem da 
bacia, na unidade hidrográfica de estudo, foi de $0,90 \mathrm{~km} / \mathrm{km}^{2}$, classificada como Pouca Drenada (Tabela 1). Segundo Linsley, Kohler e Paulhus (1975), bacias com baixa drenagem possuem solos mais resistentes à erosão ou são mais permeáveis e o relevo tende a ser mais suave, que, por sua vez, acabam contribuindo para que o escoamento pluvial ocorra de forma mais lenta. Borsato e Martoni (2004) explicam que o estudo dos fatores de declividade e grau de impermeabilização das vertentes são fundamentais para compreender o escoamento superficial em bacias de baixa drenagem.

Por sua vez, a extensão do Percurso Superficial foi de $0,55 \mathrm{~km}$, indicando que a distância média percorrida pelas enxurradas até um canal permanente é pequena, assim, colaborando para o escoamento superficial da BHPJ de forma mais rápida (Tabela 1).

Todavia, a BHPJ possui alto Coeficiente de Manutenção, pois a área mínima para manter um metro quadrado de canal de escoamento foi de $1,11 \mathrm{~km} / \mathrm{km}^{2}$ (Tabela 1), o que contrapõe o resultado obtido na Extensão do Percurso Superficial, uma vez que ele relaciona apenas a distância média que a água escoa em linha reta até o canal mais próximo, enquanto que o Coeficiente de Manutenção fornece a área mínima necessária para manter um metro de canal de escoamento (CHRISTOFOLETTI, 1981; BORSATO; MARTONI, 2004). Ainda assim, ambos os parâmetros não consideram a declividade dos canais e da bacia, mas ajudam a compreender a dinâmica do sistema de drenagem da BHPJ.

Conforme o ordenamento hierárquico de canais, proposto por Strahler (1957 apud CHRISTOFOLETTI, 1981), a BHPJ é classificada como de $8^{\circ}$ ordem (Figura 2).

Os resultados indicaram que $73,40 \%$ dos canais são de $1^{\circ}$ ordem, Laszlo e Rocha (2014) explicam que a frequência predominante de canais de $1^{\circ}$ ordem em bacias hidrográficas indica relevos com acentuados graus de dissecação, os quais possibilitam inferir sobre a evolução da rede de drenagem na bacia hidrográfica, uma vez que os canais dessa ordem representam as nascentes da bacia (Tabela 2). 


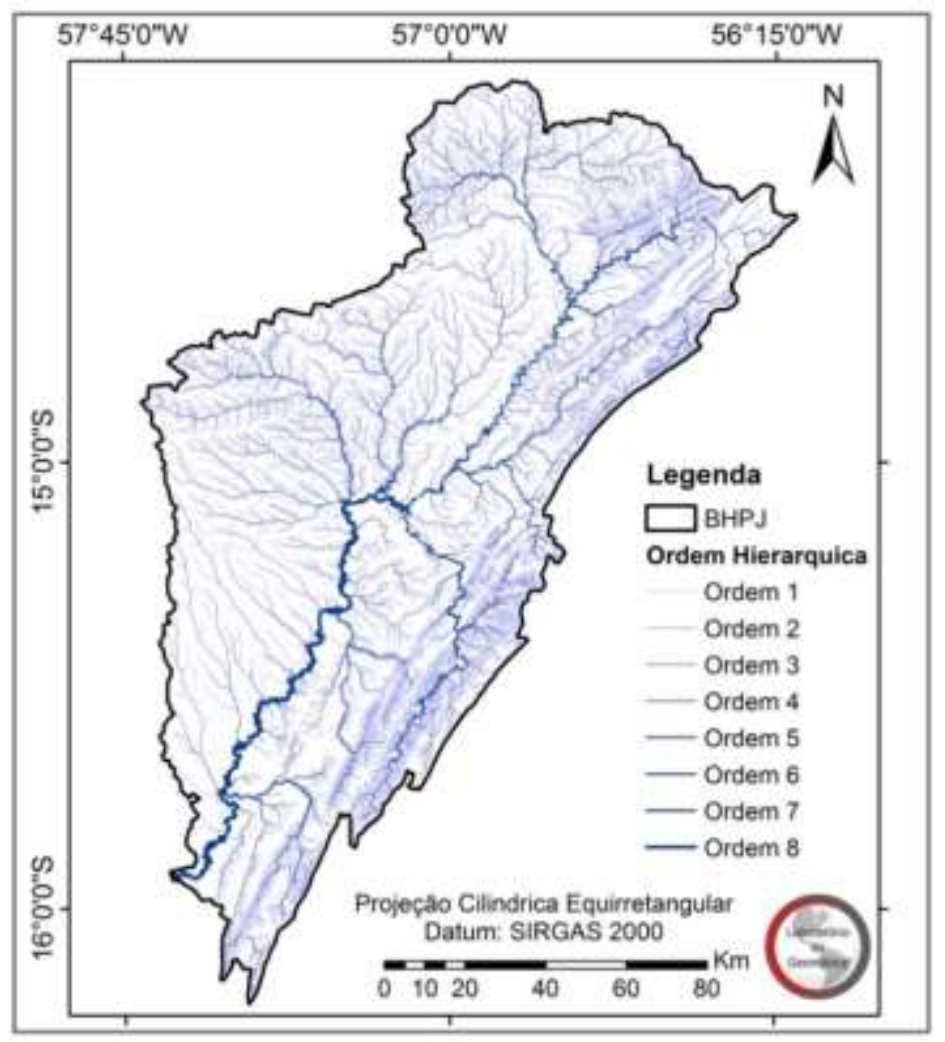

Figura 2 - Hierarquia fluvial da Bacia Hidrográfica Paraguai/Jauquara

Na BHPJ, a média da Relação de Bifurcação foi de 3,81, demonstrando que a rede de drenagem possui acentuada bifurcação e indica que em algumas regiões o relevo é mais íngreme, desse modo, tornando os canais mais propensos à erosão (Tabela 2) (BARBOSA; FURRIER, 2011).

Tabela 2 - Caracterização linear da Bacia Hidrográfica Paraguai/Jauquara

\begin{tabular}{|c|c|c|c|c|}
\hline \multicolumn{5}{|c|}{ Parâmetros lineares } \\
\hline $\begin{array}{l}\text { Hierarquia } \\
\text { fluvial }\end{array}$ & $\begin{array}{l}\text { Número } \\
\text { de canais }\end{array}$ & $\begin{array}{l}\text { Frequência } \\
\text { de canais (\%) }\end{array}$ & $\begin{array}{l}\text { Relação de } \\
\text { bifurcação }\end{array}$ & $\begin{array}{c}\text { Comprimento } \\
\text { médio dos } \\
\text { canais }(\mathbf{k m})\end{array}$ \\
\hline 1 & 8737 & 73,40 & 3,63 & 0,88 \\
\hline 2 & 2409 & 20,24 & 4,36 & 1,41 \\
\hline 3 & 553 & 4,65 & 3,39 & 3,12 \\
\hline 4 & 163 & 1,37 & 5,62 & 4,85 \\
\hline 5 & 29 & 0,24 & 3,22 & 19,99 \\
\hline 6 & 9 & 0,08 & 4,50 & 28,53 \\
\hline 7 & 2 & 0,02 & 2,00 & 90,45 \\
\hline 8 & 1 & 0,01 & - & 262,17 \\
\hline Total & 11.903 & 100 & - & 411,412 \\
\hline
\end{tabular}

Os canais de $1^{\circ}$ ordem, que possuem o menor Comprimento Médio, predominam na bacia investigada, indicando que suas águas escoam em uma distância relativamente curta até os canais de ordem imediatamente superior (Tabela 2). Observa-se que o comprimento médio dos canais aumenta para cada ordem hierárquica, esse padrão pode ser explicado pela lei dos comprimentos dos 
canais de Horton (1945), em que o canal de ordem mais elevada pode ser considerado o canal principal de uma bacia hidrográfica.

$\mathrm{Na}$ BHPJ foi identificado o Rio Paraguai como canal principal, com extensão de $480,36 \mathrm{~km}$ ao longo da bacia, cuja vegetação nativa em sua APP encontra-se preservada, conforme previsto na Lei Federal n. ${ }^{\circ}$ 12651/2012 (BRASIL, 2012). O ITA obtido caracteriza o canal como Pouco Degradado (Tabela 3).

Tabela 3 - Uso e cobertura da terra em APP do Rio Paraguai na Bacia Hidrográfica Paraguai/Jauquara e seu Estado de conservação e Índice de Transformação Antrópica

\begin{tabular}{|c|c|c|c|c|}
\hline $\begin{array}{l}\text { Classes de uso e } \\
\text { cobertura da terra }\end{array}$ & $\begin{array}{l}\text { Área } \\
\left(\mathrm{km}^{2}\right)\end{array}$ & $\begin{array}{l}\text { Área } \\
(\%)\end{array}$ & $\begin{array}{c}\text { Estado de conservação da } \\
\text { APP }\end{array}$ & ITA \\
\hline Vegetação Natural & 65,79 & 98,16 & $\begin{array}{c}\text { Em acordo com a Lei } n .^{\circ} \\
12651 / 2012 \\
\end{array}$ & \multirow{4}{*}{1,08} \\
\hline Pastagem & 1,18 & 1,76 & Em conflito com a Lei $n .{ }^{\circ}$ & \\
\hline Outros usos & 0,06 & 0,08 & 12651/2012 & \\
\hline Total & 67,03 & 100 & - & \\
\hline
\end{tabular}

O estado de conservação da APP do Rio Paraguai se deve ao cumprimento do preconizado na Lei Federal n. ${ }^{\circ}$ 12651/2012 (BRASIL, 2012), bem como das regiões de planícies de inundação, situadas nas porções Centro-oeste e Sul da BHPJ, dificultando o acesso e o desenvolvimento das atividades agrícolas.

Todavia, há extensões da APP em conflito com a legislação (Tabela 3) devido à inserção de Pastagem e outros usos, excetuando a área urbana de Barra do Bugres, que ocupa uma área de 5,90ha da APP do Rio Paraguai (Figura 3).

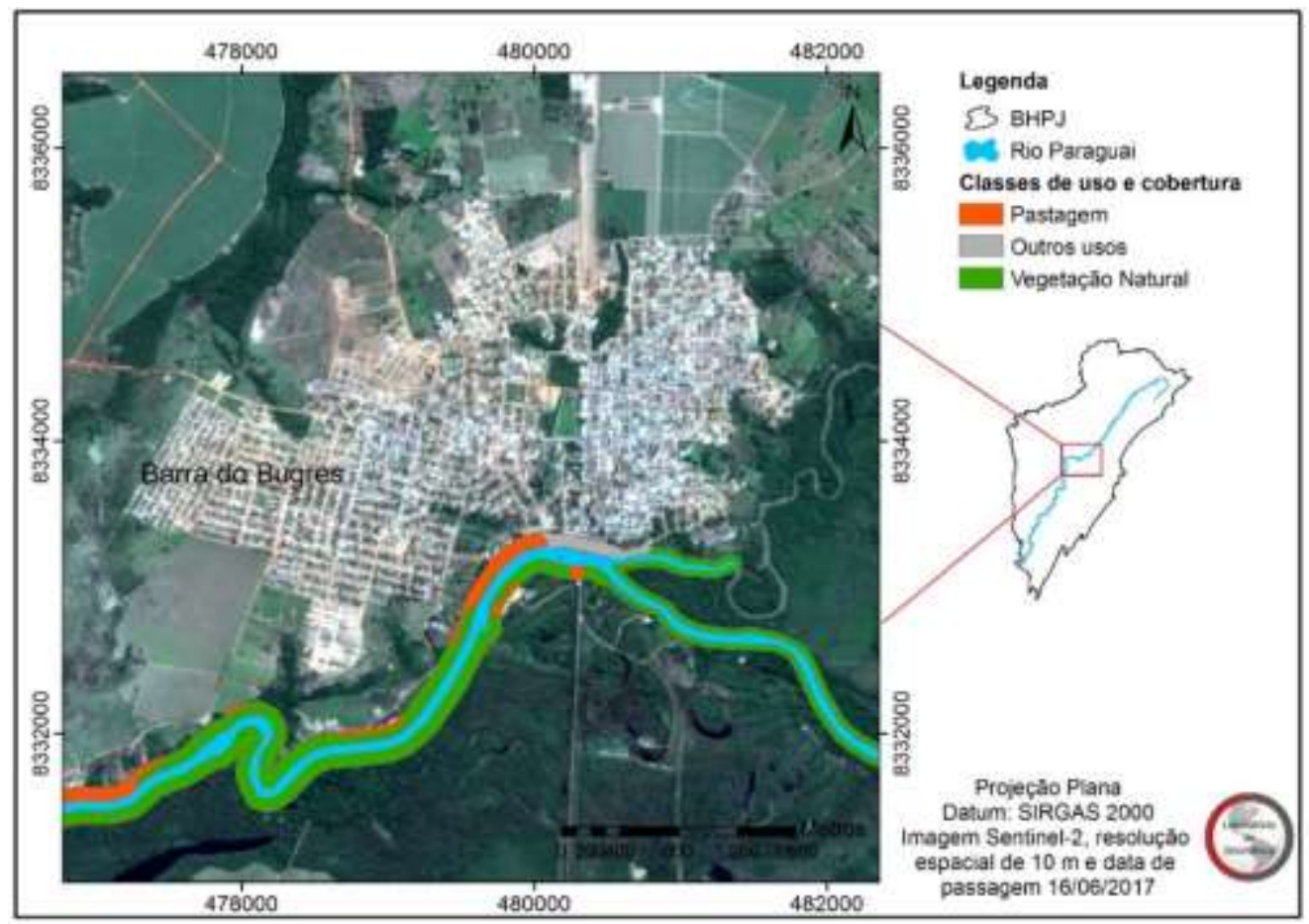

Figura 3 - APP do Rio Paraguai em conflito com a Lei Federal n. ${ }^{0} 12651 / 2012$ na BHPJ, no trecho da cidade de Barra do Bugres/MT 
As áreas em conflito não cumprem o papel fundamental de uma mata ciliar, que é a proteção do recurso hídrico (BRASIL, 2012), implicando em incremento da carga de sedimentos e agentes poluidores que desqualificam a água e alteram sua dinâmica hídrica (TUCCI, 2001). Oliveira Filho, Dutra e Ceruti (2012) acrescentam que essas alterações não ocasionam impactos apenas em um local ou ponto de uma bacia hidrográfica, mas em toda região de domínio da área de drenagem.

Exemplo do exposto ocorre quando há o aumento de carga de sedimentos combinado à compartimentação litológica, estrutura geológica e declividade que podem tornar, ao longo do tempo, canais retilíneos em sinuosos (LANA; ALVES; CASTRO, 2001; ANTONELI; THOMAZ, 2007). O Índice de Sinuosidade apresentado pelo Rio Paraguai foi de 2,29, indicando que é um canal é sinuoso. Outro ponto que reforça essa condição é o Gradiente do Canal Principal que revelou uma baixa declividade $(0,89 \%)$ decorrente de o relevo ser Plano a Suave (Figura 4), caracterizando a bacia como Pouco Drenada, pois, segundo Santo e Morais (2012), bacias com baixa declividade possuem menor poder erosivo do solo, contribuindo para que o escoamento superficial seja mais lento.

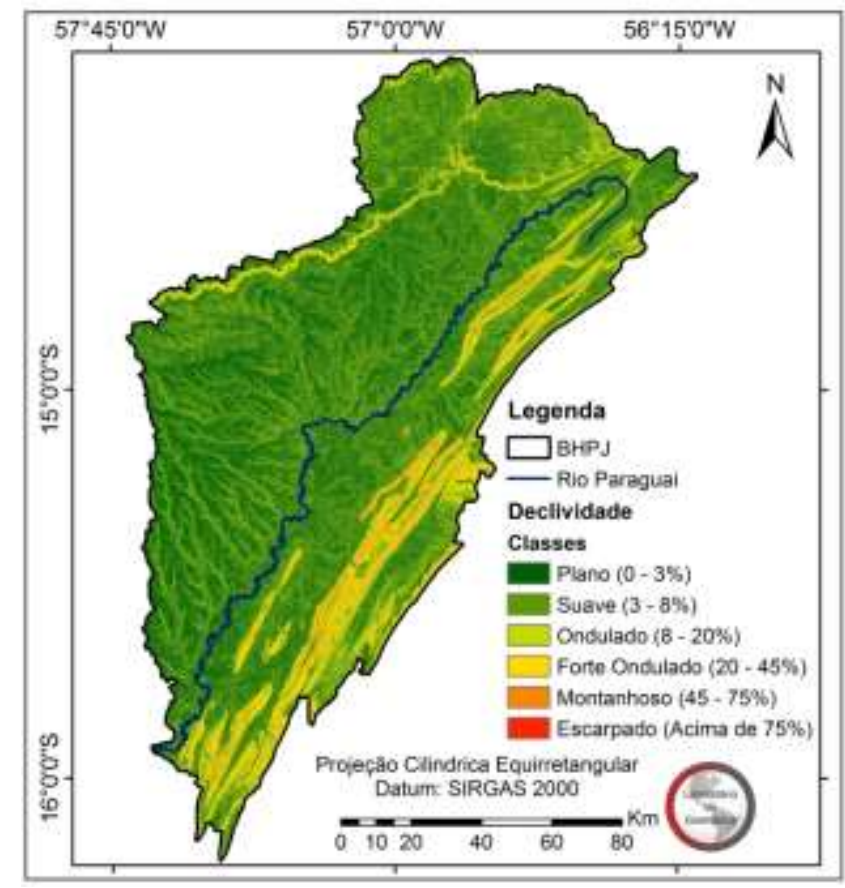

Figura 4 - Gradiente do canal principal da Bacia Hidrográfica Paraguai/Jauquara

A Curva Hipsométrica indica que $67,89 \%\left(11.189 \mathrm{~km}^{2}\right)$ da área de drenagem da BHPJ situam-se em altitudes que variam entre 100 e $300 \mathrm{~m}$ e $0,617 \%\left(101 \mathrm{~km}^{2}\right)$ 
estão em superfícies situadas em altitudes superiores a 700m próximas ao limite do divisor topográfico, onde o relevo é mais dissecado (Figura 5).

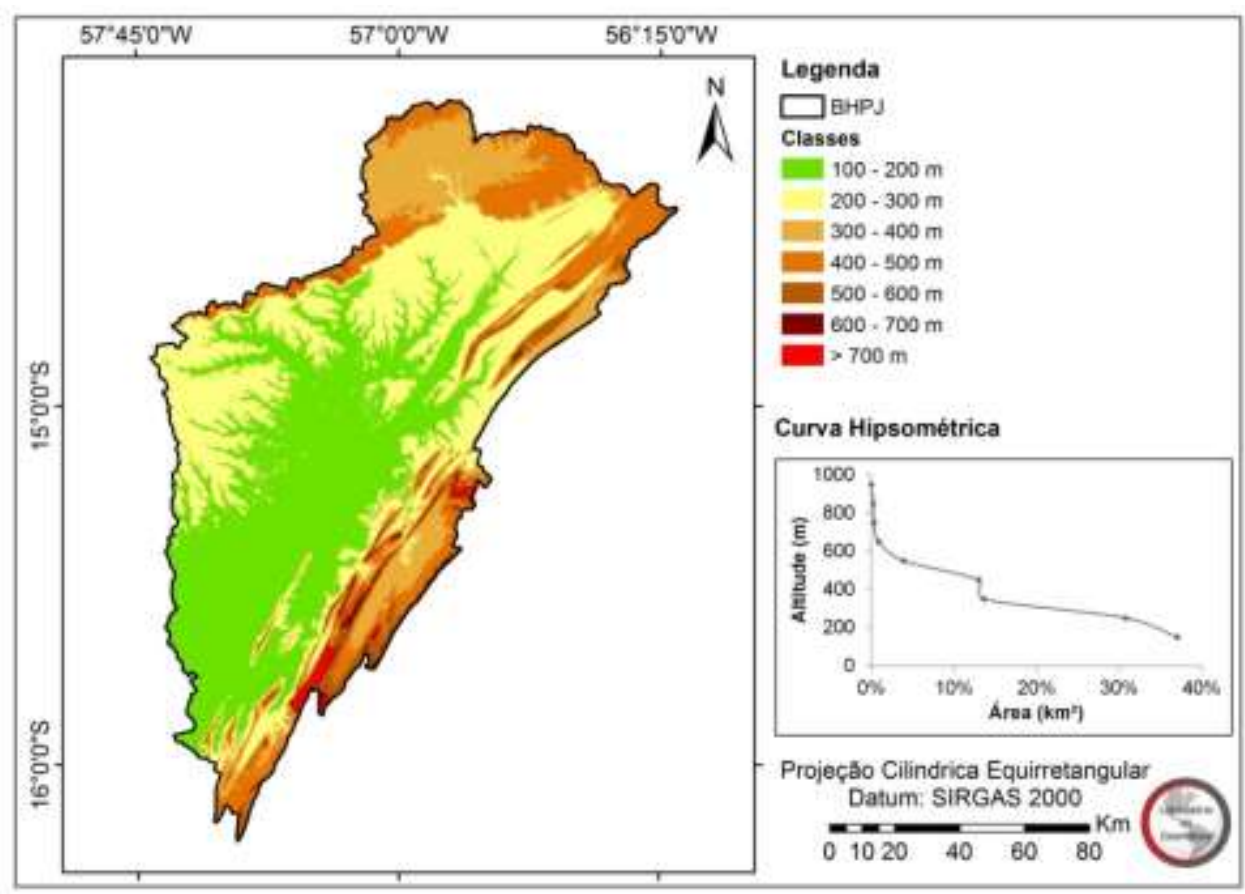

Figura 5 - Curva Hipsométrica e mapa altimétrico da Bacia Hidrográfica Paraguai/Jauquara

As variações de altitudes na BHPJ influenciam na temperatura, precipitação, evaporação e transpiração, pois essas variações, segundo Woodcock (1976 apud BORSATO; MARTONI, 2004), fazem com que a temperatura diminua $1^{\circ} \mathrm{C}$ para cada $150 \mathrm{~m}$ de altitude. Todavia, a redução da temperatura depende da umidade relativa do ar, podendo acarretar diferenças na evapotranspiração e no regime pluviométrico, o que pode influenciar diretamente o ciclo hidrológico de uma bacia hidrográfica (VILLELA; MATTOS, 1975).

Destarte, os resultados dos parâmetros morfométricos Índice de Sinuosidade, Gradiente do Canal Principal e Curva Hipsométrica analisados neste estudo apontam que a BHPJ possui escoamento superficial lento. Segundo Tucci (2001), a qualidade da água depende da velocidade do escoamento de um canal, pois, em contato com um agente poluidor e dependendo de sua concentração, um canal lento sedimentará e/ou diluirá o poluente, em dias ou meses, logo, reduzindo o poder de dispersão dele.

Embora a BHPJ apresente deficiência na capacidade de manutenção hídrica e baixa capacidade de drenagem, suas características morfométricas favorecem a manutenção e a qualidade das águas, que fazem com que ocorra o pulso de inundação do Pantanal mato-grossense pelo Rio Paraguai e seus afluentes. 


\section{Considerações Finais}

As análises das características aerais permitiram deduzir que a área de estudo possui baixa propensão à ocorrência de enchentes e inundações devido à sua forma geométrica, contribuindo para que o regime pluviométrico não exceda a capacidade de escoamento da bacia.

O sistema de drenagem também colabora para que não ocorram esses fenômenos, pois o tipo de drenagem da bacia indica que o solo é mais resistente à erosão, é mais permeável, e o relevo tende a ser mais suave.

Embora a BHPJ não seja propensa à ocorrência de enchentes e inundações, a densidade de drenagem e a capacidade de gerar novos canais da bacia são deficientes e, consequentemente, a área mínima para manter um metro de canal de escoamento é alta. Essas condições causam preocupação, pois isso significa que a manutenção em longo prazo do sistema de drenagem da bacia pode ser ineficiente e afetar a dinâmica hídrica, o uso múltiplo das águas e influenciar no pulso de inundação do Pantanal mato-grossense, cujo ecossistema é dependente das águas advindas de regiões do Planalto.

A análise dos parâmetros lineares evidenciou a predominância de canais de $1^{\circ}$ ordem, indicando a existência de elevada quantidade de nascentes e acentuada bifurcação.

Na bacia, o Rio Paraguai foi caracterizado como canal principal, considerado sinuoso, com baixo gradiente de declividade, escoamento superficial lento e está pouco degradado. Contudo, áreas de mata ciliar foram suprimidas, havendo a inserção de usos antrópicos, que podem colaborar para o incremento de sedimentos e agentes poluidores.

Em vista dos apontamentos apresentados, sugere-se que sejam desenvolvidas pesquisas que investiguem a interação das características geomorfológicas, o uso e a cobertura da terra e as variações de altitude no tocante aos fenômenos de erosão, lixiviação, sedimentação e assoreamento dos recursos hídricos da bacia.

\section{REFERÊNCIAS}

ANTONELI, V.; THOMAZ, E. L. Caracterização do meio físico da Bacia do Arroio Boa Vista - Guamiranga-PR. Revista Caminhos da Geografia, v. 8, n. 21, p. 46-58, 2007. 
BARBOSA, M. E.; FURRIER, M. Caracterização geomorfológica com apoio de índices morfométricos: O estudo de caso da Bacia do Rio Guruji. Revista Cadernos do Logepa, v. 6, n.1, p. 1-24, 2011.

BORSATO, F. H.; MARTONI, A. M. Estudo da fisiografia das bacias hidrográficas urbanas no município de Maringá, Estado do Paraná. Revista Acta Scientiarum, v. 26, n. 2, p. 273-285, 2004.

BRASIL. Agência Nacional de Águas, 2018. Superintendência de Gestão da Rede Hidrometeorológica, 2018. Disponível em:

$<$ http://www.snirh.gov.br/hidroweb/publico/baixar documento.jsf >. Acesso em 27 jul. 2018.

BRASIL. Decreto n.․ 87222, de 31 de maio de 1982. Cria as Estações Ecológicas do Seridó, Serra das Araras, Guaraqueçaba, Caracaraí e dá outras providências. Diário Oficial da União, Brasília, DF, 31 maio 1996. Disponível em:

$<$ http://www.planalto.gov.br/ccivil 03/decreto/1980-1989/D87222.htm>. Acesso em 06 jan. 2019.

BRASIL. Instituto Brasileiro de Geografia e Estatística. Mapa de Biomas do Brasil (Primeira Aproximação). Rio de Janeiro: IBGE, 2004.

BRASIL. Lei Federal 12.651, de 25 de maio de 2012. Proteção de vegetação nativa. Diário Oficial da União, Brasília, DF, 25 maio 2012. Disponível em:

$<$ http://www.planalto.gov.br/ccivil 03/ ato2011-2014/2012/lei/12651.htm>. Acesso em 23 out. 2018.

BRASIL. Lei Federal 9.433, de 08 de janeiro de 1997. Política Nacional de Recursos Hídricos. Diário Oficial da União, Brasília, DF, 8 jan. 1997. Disponível em: <http://www.planalto.gov.br/ccivil 03/leis/L9433.htm>. Acesso em 4 dez. 2017.

CÂMARA, G. et al. Spring: Integrating Remote Sensing and GIS with ObjectOriented Data Modelling. Computers and Graphics, Dordrecht/NL, v. 20, n. 3, p. 395-403, 1996.

CASARIN, R.; NEVES, S. M. A. S.; NEVES, R. J. Uso da terra e qualidade da água da bacia hidrográfica Paraguai/Jauquara-MT. Revista Geografia Acadêmica, v. 2, n. 1, p. 33-42, 2008.

CHRISTOFOLETTI, A. Geomorfologia. 2. ed. São Paulo: Edgard Blucher, 1981. CRUZ, C. B. M. et al. Carga antrópica da bacia hidrográfica da Baía de Guanabara. In: SIMPÓSIO BRASILEIRO DE SENSORIAMENTO REMOTO, 9., 1998, Santos, Anais [...] Santos: SBSR, 1998. Disponível em: $<$ http://marte.sid.inpe.br/col/sid.inpe.br/deise/1999/02.09.11.15/doc/4 48p.pdf>. Acesso em: 23 out. 2018.

ESRI. ArcGIS Desktop: release 10.3. Redlands, CA: Environmental Systems, 2007.

FENNER, W. et al. S. Análise do balanço hídrico mensal para regiões de transição de Cerrado-Floresta e Pantanal, Estado de Mato Grosso. Revista Acta, v. 3, n.1, p. 72-85, 2014. 
HORTON, R. E. Erosional development of streams and their drainage basins: hydrophysical approach to quantitative morphology. Bulletin of the Geological Society of America, v. 56, n. 3, p. 275-370, 1945.

INSTITUTO BRASILEIRO DE GEOGRAFIA E ESTATÍSTICA - IBGE. Manual técnico da vegetação brasileira. 3. ed. Rio de Janeiro: IBGE, 2012.

LANA, C. E.; ALVES, J. M. P.; CASTRO, P. T. A. Análise morfométrica da bacia do Rio do Tanque, MG - Brasil. Revista Escola de Minas, v. 54, n. 2, p. 121-126, 2001.

LASZLO, M.; ROCHA, P. C. Composição hierárquica dos canais fluviais das bacias hidrográficas dos rios Aguapeí e Peixe. Revista Geonorte, v. 10, n. 1, p. 228-232, 2014.

LÉMECHEV, T. On hydrological heterogeneity catchment morphology and catchment response. Journal of Hydrology, v.100, n. 1, p. 357- 375. 1982.

LINSLEY, R.K. J. KOHLER, M. A.; PAULHUS, J. L.H. Hydrology for Engineers, 2. ed. New York: McGraw-Hill, 1975.

MATO GROSSO (Estado). Secretaria de Estado de Planejamento, 2017. Regiões de Planejamento de Mato Grosso. Cuiabá - MT: SEP, 2017.

OLIVEIRA FILHO, P. C.; DUTRA, A. M.; CERUTI, F. C. Qualidade das Águas Superficiais e o Uso da Terra: Estudo de Caso Pontual em Bacia Hidrográfica do Oeste do Paraná. Revista Floresta e Ambiente, v. 19, n. 1, p. 32-43, 2012.

PESSOA, S. P. M. et al.. Análise espaço-temporal da cobertura vegetal e uso da terra na Interbacia do Rio Paraguai Médio-MT, Brasil. Revista Árvore, v. 37, n.1, p. 119-128, 2013.

QGIS Development Team. 2016. QGIS 2.14.0 Essien. Geographic Information System. Open Source Geospatial Foundation Project. Research Institute, 2007.

RIBEIRO, H. V.; GALVANIN, E. A. S.; PAIVA, M. M. Análise das pressões antrópicas na bacia Paraguai/Jauquara-Mato Grosso. Revista Ciência e Natura, v. 39, n. 2, p. 378-389, 2017.

SANTOS, D. A. R.; MORAIS, F. Análise morfométrica da bacia hidrográfica do rio Lago Verde como subsídio à compartimentação do relevo da Região de Lagoa da Confusão - TO. Revista Geonorte, v. 3, n. 4, p. 617-629, 2012.

SANTOS, G. V. et al. Análise hidrológica e socioambiental da bacia hidrográfica do Córrego Romão dos Reis, Viçosa-MG. Revista Árvore, v. 31, n. 5, p. 931-940, 2007.

SANTOS, H. G.et al. Sistema brasileiro de classificação de solos. 5. ed. Brasília/Rio de Janeiro: EMBRAPA, 2013.

SOARES, L. S. et al. C. Análise morfométrica e priorização de bacias hidrográficas como instrumento de planejamento ambiental integrado. Revista do Departamento de Geografia, v. 31, n. 1, p. 82-100, 2016. 
TEODORO. L. I. et al. O conceito de bacia hidrográfica e a importância da caracterização morfométrica para o entendimento da dinâmica ambiental local. Revista Uniara, v. 11, n. 1, p. 136-156, 2007.

TUCCI, C. E. M. Hidrologia: Ciência e Aplicação. 2. ed. Porto Alegre: Universidade Federal do Rio Grande do Sul, 2001.

USGS. Geological Survey. Disponível em:<http://landsat.usgs.gov $>$. Acesso em: 09 jan. 2018.

VILLELA, S. M.; MATTOS, A. Hidrologia Aplicada. São Paulo: McGraw-Hill, 1975.

WISLER, C. O.; BRATER, E. F. Hidrologia. Tradução e publicação de Missão NorteAmericana pela Cooperação Econômica e Técnica no Brasil. Rio de Janeiro: Ao Livro Técnico, 1964.

\section{NOTAS DE AUTOR}

\section{CONTRIBUIÇÃO DE AUTORIA}

Edinéia Aparecida dos Santos Galvanin - Concepção. Coleta de dados, Análise de dados, Elaboração do manuscrito, revisão e aprovação da versão final do trabalho

Sandra Mara Alves da Silva Neves - Elaboração do manuscrito. Coleta de dados. Participação na discussão dos resultados; Revisão.

\section{FINANCIAMENTO}

Bolsa de pós-graduação pela Coordenação de Aperfeiçoamento de Pessoal de Nível Superior - CAPES.

\section{CONSENTIMENTO DE USO DE IMAGEM}

Não se aplica.

\section{APROVAÇÃO DE COMITÊ DE ÉTICA EM PESQUISA}

Não se aplica.

\section{CONFLITO DE INTERESSES}

Não se aplica.

\section{LICENÇA DE USO}

Este artigo está licenciado sob a Licença Creative Commons CC-BY-NC. Com essa licença você pode compartilhar, adaptar, criar para qualquer fim, sem uso comercial e desde que atribua a autoria da obra.

\section{HISTÓRICO}

Recebido em: 17-02-2019

Aprovado em: 31-10-2019 